\title{
Individual and Combined Relationship between Reduced eGFR and/or Increased Urinary Albumin Excretion Rate with Mortality Risk among Insulin-Treated Patients with Type 2 Diabetes in Routine Practice
}

\author{
Uchenna Anyanwagu Richard Donnelly Iskandar Idris \\ Division of Graduate Entry Medicine, School of Medicine, University of Nottingham, Nottingham, UK
}

\author{
Keywords \\ Estimated glomerular filtration rate $\cdot$ Mortality risk · Urinary \\ albumin-to-creatinine ratio $\cdot$ Type 2 diabetes
}

\begin{abstract}
Background: A low estimated glomerular filtration rate (eGFR) and an increased urinary albumin-to-creatinine ratio (ACR) are well-recognised prognostic markers of cardiovascular (CV) risk, but their individual and combined relationship with CV disease and total mortality among insulin-treated type 2 diabetes (T2D) patients in routine clinical care is unclear. Methods: We analysed data for insulin users with T2D from UK general practices between 2007 and 2014 and examined the association between mortality rates and chronic kidney disease [categorised by low eGFR ( $<60 \mathrm{~mL}$ / $\left.\mathrm{min} / 1.73 \mathrm{~m}^{2}\right)$, high eGFR $\left(\geq 60 \mathrm{~mL} / \mathrm{min} / 1.73 \mathrm{~m}^{2}\right)$, low ACR ( $<300 \mathrm{mg} / \mathrm{g})$; and high ACR ( $\geq 300 \mathrm{mg} / \mathrm{g}$ ) at insulin initiation] after a 5-year follow-up period using Cox proportional hazard models. Results: A total of 18,227 patients were identified (mean age: $61.5 \pm 13.8$ years, mean HbA1c: $8.6 \pm 1.8 \%$ ). After adjusting for confounders, when compared to adults on insulin therapy with an eGFR $<60$ and an ACR $\geq 300$ (low eGFR + high ACR) after a follow-up period of 5 years, patients with an eGFR $<60$ and an ACR $<300$ (low eGFR + low ACR)
\end{abstract}

had a $6 \%$ lower mortality rate (aHR: $0.94 ; 95 \% \mathrm{Cl} 0.79-1.12$ ); those with an eGFR $>60$ and an ACR $\geq 300$ (high eGFR + high ACR) had a $20 \%$ lower mortality rate (aHR: 0.80 ; $95 \% \mathrm{Cl} 0.68-$ 0.96); and those with an eGFR $>60$ and an ACR $<300$ (high eGFR + low ACR) had the lowest death rate (28\% less; aHR: $0.72 ; 95 \% \mathrm{Cl} 0.59-0.87)$. Conclusion: This study shows that among a large cohort of insulin-treated T2D patients in routine practice, the combination of reduced eGFR with increased ACR was associated with the greatest risk of premature death, followed closely by those with reduced eGFR and normal ACR levels. Adoption of aggressive CV risk management strategies to reduce mortality in patients with a low eGFR and albuminuria is essential in high-risk patients with T2D.

(c) 2018 S. Karger AG, Basel

\section{Introduction}

Several high-impact studies have identified the elevated risk of end-stage renal disease (ESRD) and cardiovascular $(\mathrm{CV})$ disease conferred by albuminuria in addition to the estimated glomerular filtration rate (eGFR) [1-4]. These two distinct but complimentary methods to assess for the presence of chronic kidney disease (c) 2018 S. Karger AG, Basel

E-Mail karger@karger.com

www.karger.com/kdd
Dr Iskandar Idris

Division of Graduate Entry Medicine, School of Medicine

University of Nottingham, Royal Derby Hospital Centre

Uttoxeter Road, Derby DE22 3DT (UK)

E-Mail Iskandar.idris@ nottingham.ac.uk 
(CKD) are widely used in routine clinical practice, with CKD due to diabetic nephropathy affecting $30-40 \%$ of patients with type 2 diabetes (T2D) [5]. Albuminuria is typically assessed by the urinary albumin-to-creatinine ratio (ACR). An elevated ACR denotes the presence of CKD, independent of eGFR categories [6, 7]. ACR levels between 30 and $300 \mathrm{mg} / \mathrm{g}$ represent moderately increased levels of albuminuria, known as microalbuminuria, while levels of more than $300 \mathrm{mg} / \mathrm{g}$ are associated with frank proteinuria. eGFR is a key indicator of renal function and is mathematically derived based on a patient's serum creatinine level, age, sex, and race and calculated using the well-validated formulae derived from the Modification of Diet in Renal Disease (MDRD) CKD-EPI equations [8]. "Normal" eGFR is usually $>90$ $\mathrm{mL} / \mathrm{min} / 1.73 \mathrm{~m}^{2}$, corrected for body surface area "per

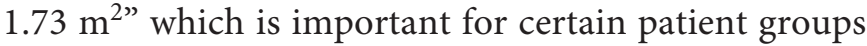
(e.g., amputees, extremes of body habitus). However, in the absence of any marker of kidney damage, eGFR is only classified as CKD if its value is $<60 \mathrm{~mL} / \mathrm{min} /$ $1.73 \mathrm{~m}^{2}[9]$.

For many patients with $\mathrm{T} 2 \mathrm{D}$, insulin treatment will be required to control hyperglycaemia and to reduce the risk of long-term vascular complications [10-12]. However, insulin therapy is known to induce $\sim 4-9 \mathrm{~kg}$ weight gain in the first year of treatment. [13] This is relevant within the context of diabetic nephropathy, since obesity per se is a significant risk factor for the appearance of proteinuria and ESRD [14]. Furthermore, recent evidence from randomized controlled trials, epidemiological and observational studies have implicated insulin therapy in patients with T2D with increased CV risk and mortality [15-18], possibly due to weight gain, recurrent hypoglycaemia, other potential adverse effects such as iatrogenic hyperinsulinemia as well as a surrogate marker of increased diabetes duration $[19,20]$. Thus, a cohort of insulin-treated patients with $\mathrm{T} 2 \mathrm{D}$, represent a complex heterogenous, challenging group of patients, many of whom have significant comorbidities and high CV disease risk. No studies have assessed the relative strength of increments in urinary ACR and/or decrement in eGFR in predicting total mortality among insulin-treated patients with $\mathrm{T} 2 \mathrm{D}$ in routine clinical care.

\section{Methods}

\section{Study Design}

We conducted a retrospective cohort study using the UK primary care electronic database called The Health Improvement Network (THIN) Database.
THIN comprises longitudinal records which were obtained from about 587 general practices and updated periodically. It contains medical information of over 12.4 million patients in which approximately 3.61 million are active users. Trained doctors and specialist nurses systematically enter routine clinical information into this database. These range from specialist medical consultations, diagnoses, laboratory results, prescriptions, referrals, hospital admissions, immunisations, and clinical measurements as body weight, height, and body mass index (BMI). It also has data on the patients' demography, lifestyle characteristics (e.g., alcohol use and smoking), socio-economic status (Townsend deprivation scores), ethnicity, religion, and more recently, ethnicity/languages. It has been validated and shown to be demographically representative of the UK population in terms of disease demography, prevalence, and mortality [21]. Like many others, our research group has extensively used it in evaluating diabetes-related outcomes in routine clinical practice $[22,23]$.

\section{Study Participants}

We obtained routine clinical data on 18,227 people with a diagnosis of T2D who met our inclusion criteria. These must be aged 18 years and above; commenced insulin therapy between December 2006 and May 2014; and with recorded values of ACR and e-GFR on insulin initiation. Patients with type 1, gestational diabetes, or other forms of diabetes; and those with no continuous records of regular insulin prescriptions were excluded.

\section{Follow-Up and Endpoints}

The baseline (insulin initiation) ACR (mg/g) and eGFR (mLs/ $\min / 1.73 \mathrm{~m}^{2}$ ) levels were used to categorise the patients into four treatment groups:

- Group 1: low eGFR + high ACR - those with eGFR $<60$ and an ACR $\geq 300$

- Group 2: low eGFR + low ACR - those with eGFR $<60$ and an ACR $<300$

- Group 3: high eGFR + high ACR - those with eGFR $\geq 60$ and an $A C R \geq 300$

- Group 4: high eGFR + low ACR - those with eGFR $\geq 60$ and an ACR $<300$

The primary endpoint was all-cause mortality. Secondary endpoints were the risks of $\mathrm{CV}$ events (non-fatal stroke and myocardial infarction) and a 3-point composite of MACE (Major Adverse CV Event - all-cause mortality, non-fatal myocardial infarction, and stroke).

From the baseline period, these groups were followed up until the first of the occurrence of any of the outcomes; or loss to followup; or discontinuation of insulin therapy; or at the end of the 5-year follow-up period.

\section{Baseline and Endpoint Characteristics}

We also obtained data on important clinical covariates that confound the association between the exposure and outcome variables. This is based on a priori knowledge and from the tests of association. Significant covariates were fitted in the final model in order to adjust for their possible confounding effects. Therefore, data were extracted for demographic variables such as age, gender, socioeconomic status, alcohol and smoking status; important clinical measures such as body weight, height, SBP, and DBP; biochemical parameters, e.g., baseline $\mathrm{HbAlc}$, lipid-profile, use of other medications including other glucose-lowering therapies 
Table 1. Baseline characteristics

\begin{tabular}{|c|c|c|c|c|c|}
\hline Categories & $\begin{array}{l}\text { Group 1: } \\
\text { low eGFR + } \\
\text { high ACR }\end{array}$ & $\begin{array}{l}\text { Group 2: } \\
\text { low eGFR + } \\
\text { low ACR }\end{array}$ & $\begin{array}{l}\text { Group 3: } \\
\text { high eGFR + } \\
\text { high ACR }\end{array}$ & $\begin{array}{l}\text { Group 4: } \\
\text { high eGFR + } \\
\text { low ACR }\end{array}$ & Total \\
\hline Patient number & 5,563 & 2,522 & 5,511 & 4,631 & 18,227 \\
\hline Mean age $\pm S D$, years & $67.1 \pm 11.9$ & $66.7 \pm 11.5$ & $57.7 \pm 13.5$ & $56.8 \pm 13.5$ & $61.5 \pm 13.6$ \\
\hline Male gender, $n(\%)$ & $2,820(51)$ & $1,219(48)$ & $3,079(56)$ & $2,577(56)$ & $9,695(53.2)$ \\
\hline Least deprived & $1,128(21)$ & $514(21)$ & 999 (19) & $946(21)$ & $3,587(19.7)$ \\
\hline 2nd quintile & $1,093(21)$ & $481(20)$ & $1,043(20)$ & $880(20)$ & $3,497(19.2)$ \\
\hline 3rd quintile & $1,142(21)$ & $519(21)$ & $1,116(21)$ & $953(21)$ & $3,730(20.5)$ \\
\hline 4th quintile & $1,133(21)$ & $515(21)$ & $1,160(22)$ & $955(21)$ & $3,763(20.7)$ \\
\hline Most deprived & $832(16)$ & $387(16)$ & $913(17)$ & $727(16)$ & $2,859(15.7)$ \\
\hline \multicolumn{6}{|l|}{ Smoking status, $n(\%)$} \\
\hline Non-drinker & $1,919(34)$ & $875(35)$ & $1,762(32)$ & $1,360(29)$ & $5,916(32.5)$ \\
\hline Ex-drinker & $679(12)$ & $285(11)$ & $592(11)$ & $512(11)$ & $2,068(11.4)$ \\
\hline Current drinker & $2,965(53)$ & $1,362(54)$ & $3,157(57)$ & $2,759(60)$ & $10,243(56.2)$ \\
\hline \multicolumn{6}{|l|}{ Clinical parameters } \\
\hline $\mathrm{HbA} 1 \mathrm{c}, \%[\mathrm{mmol} / \mathrm{mol}]$ & $8.7 \pm 1.8[72]$ & $8.5 \pm 1.7[67]$ & $8.8 \pm 1.9[73]$ & $8.6 \pm 1.8[70]$ & $8.7 \pm 1.8[72]$ \\
\hline BMI & $32.7 \pm 6.7$ & $32.6 \pm 6.7$ & $32.4 \pm 6.9$ & $32.3 \pm 7.0$ & $32.5 \pm 6.9$ \\
\hline Diabetes duration ${ }^{\mathrm{a}}$, years & $4.9 \pm 4.9$ & $4.9 \pm 5.4$ & $3.9 \pm 4.6$ & $3.7 \pm 4.7$ & $4.3 \pm 4.9$ \\
\hline Duration on insulin, years & $4.3 \pm 6.8$ & $4.5 \pm 6.5$ & $3.6 \pm 5.9$ & $3.6 \pm 6.1$ & $3.9 \pm 6.4$ \\
\hline Weight, kg & $91.0 \pm 18.4$ & $89.7 \pm 18.6$ & $92.2 \pm 19.2$ & $91.4 \pm 18.6$ & $91.3 \pm 18.7$ \\
\hline Height, m & $1.7 \pm 0.1$ & $1.7 \pm 0.1$ & $1.7 \pm 0.1$ & $1.7 \pm 0.1$ & $1.7 \pm 0.1$ \\
\hline $\mathrm{SBP}, \mathrm{mm} \mathrm{Hg}$ & $138.8 \pm 23.6$ & $135.9 \pm 22.6$ & $136.5 \pm 23.0$ & $133.4 \pm 22.3$ & $136.3 \pm 23.0$ \\
\hline \multicolumn{6}{|l|}{ BMI categories, $n(\%)$} \\
\hline Normal & $696(13)$ & $316(13)$ & $762(14)$ & $681(15)$ & $2,455(13.5)$ \\
\hline Overweight & $1,315(24)$ & $594(24)$ & $1,315(24)$ & $1,119(24)$ & $4,343(23.8)$ \\
\hline Obese & $3,552(64)$ & $1,612(64)$ & $3,434(62)$ & $2,831(61)$ & $11,429(62.7)$ \\
\hline \multicolumn{6}{|l|}{ GLTs, $n(\%)$} \\
\hline Metformin & $4,668(83.9)$ & $2,105(83.5)$ & $4,807(87.2)$ & $4,013(86.7)$ & $15,593(85.6)$ \\
\hline Sulphonylurea & $4,339(78.0)$ & $1,951(77.4)$ & $4,129(74.9)$ & $3,375(72.9)$ & $13,794(75.7)$ \\
\hline Thiazolidinedione & $1,696(30)$ & $755(30)$ & $1,803(33)$ & $1,500(32)$ & $5,754(31.6)$ \\
\hline GLP-1RA & $454(8)$ & $194(8)$ & $732(13)$ & $563(12)$ & $1,943(10.7)$ \\
\hline SGLT2i & $15(0)$ & $7(0)$ & $35(1)$ & $28(1)$ & $85(0.5)$ \\
\hline Glinides & $262(5)$ & $108(4)$ & $238(4)$ & $182(4)$ & $790(4.3)$ \\
\hline DPP4i & $735(13)$ & $289(11)$ & $840(15)$ & $705(15)$ & $2,569(14.1)$ \\
\hline
\end{tabular}

Reduced eGFR and Increased Urinary ACR as Powerful Determinants of Survival
Kidney Dis 2019;5:91-99 DOI: $10.1159 / 000493731$ 
Table 1 (continued)

\begin{tabular}{|c|c|c|c|c|c|}
\hline Categories & $\begin{array}{l}\text { Group 1: } \\
\text { low eGFR + } \\
\text { high ACR }\end{array}$ & $\begin{array}{l}\text { Group 2: } \\
\text { low eGFR + } \\
\text { low ACR }\end{array}$ & $\begin{array}{l}\text { Group 3: } \\
\text { high eGFR + } \\
\text { high ACR }\end{array}$ & $\begin{array}{l}\text { Group 4: } \\
\text { high eGFR + } \\
\text { low ACR }\end{array}$ & Total \\
\hline Aspirin & $5,459(98)$ & $2,468(97)$ & $5,232(96)$ & $4,348(98)$ & $17,507(96.1)$ \\
\hline Antihypertensive & $5,175(95)$ & $2,332(94)$ & $4,634(89)$ & $3,795(87)$ & $15,936(87.4)$ \\
\hline ACE inhibitors & $4,616(85)$ & $2,073(84)$ & $4,043(77)$ & $3,291(76)$ & $14,023(80)$ \\
\hline Calcium channel blockers & $3,363(62)$ & $1,478(60)$ & $2,693(52)$ & $2,110(49)$ & $9,644(55)$ \\
\hline Beta-blockers & $3,085(57)$ & $1,352(55)$ & $2,421(46)$ & $2,020(46)$ & $8,878(51)$ \\
\hline LLTs & $4,955(91)$ & $2,257(91)$ & $4,799(92)$ & $3,965(91)$ & $15,976(87.7)$ \\
\hline \multicolumn{6}{|l|}{ Comorbidities, $n(\%)$} \\
\hline $\mathrm{CHD}$ & $2,003(36)$ & $906(36)$ & $1,393(25)$ & $1,158(25)$ & $5,460(30.0)$ \\
\hline PAD & $924(17)$ & $395(16)$ & $626(11)$ & $463(10)$ & $2,408(13.2)$ \\
\hline
\end{tabular}

GLP-1RA, glucagon-like peptide-1 receptor agonist; SGLT2i, sodium-glucose cotransporter-2 inhibitors; DPP4i, dipeptidyl-peptidase 4 inhibitors; GLTs, glucose-lowering therapies; BMI, body mass index; SBP, systolic blood pressure; DBP, diastolic blood pressure; HbA1c, haemoglobin A1c; HDL, high-density lipoprotein; LDL, low-density lipoprotein; TC, total cholesterol; eGFR, estimated glomerular filtration rate; LLTs, lipid-lowering therapies; PAD, peripheral artery disease; CHD, coronary heart disease; ACR, albuminto-creatinine ratio; $\mathrm{ACEi}$, angiotensin-converting enzyme inhibitors; ARBs, angiotensin II receptor blockers; SD, standard deviation. a Diabetes duration is the period between the diagnosis of diabetes to the initiation of insulin therapy.

(GLTs); as well as comorbidity status, duration of diabetes treatment, and duration of insulin use. These were included in our univariate analysis models from which significant covariates (those which had a significant association with both the exposure and outcomes) were added to the final Cox models.

\section{Statistical Analysis}

Subjects with missing values for eGFR and ACR at baseline were further excluded. A small proportion of HbAlc, eGFR, weight, SBP, and DBP records at baseline were completely missing at random (MAR). These missing values were then computed by multiple imputations using the chained equation (MICE) model.

We computed summary data for the mean, standard deviations, and proportions of the baseline characteristics. Differences between the baseline categorical and continuous variables within the four groups were compared using the Pearson $\chi^{2}$ test and linear regression, respectively. Mortality rates were presented as 5-year Kaplan-Meier estimates. The Cox proportional hazard model was used to estimate the marginal and adjusted mortality ratios (HRs) with 95\% confidence intervals, comparing the mortality in all groups to group 1 (low eGFR + high ACR). In our multivariate Cox regression models in which we evaluated the association between poor renal function and all-cause mortality, the identified significant baseline covariates were included.

Further, we performed the Cox regression analysis to explore the risk of CVs (non-fatal stroke and myocardial infarction) and a 3-point composite of MACE (Major Adverse CV), including allcause mortality, non-fatal myocardial infarction, as well as stroke, in the patient groups. We tested for violations of the proportional hazard assumption of the Cox regression model, first by adding an interaction term of the predictor; secondly by log-minus-log survival curves; and thirdly by Schoenfeld residuals tests. All point estimates were computed with $95 \%$ confidence intervals (CI) at the conventional statistical significance level of 0.05, using Stata Software version 15 .

\section{Results}

\section{Patient Characteristics}

Only 18,227 patients in the dataset met our inclusion criteria in which group 2 had the least number of patients $(13.8 \%)$. The overall mean age was $61.5 \pm 14$ years. Slightly above half (53.2\%) of the population were males. The overall mean $\mathrm{HbA} 1 \mathrm{c}$ and BMI were $8.7 \pm 1.8 \%$ (72 mmol/ $\mathrm{mol}$ ) and $32.5 \pm 6.9 \mathrm{~kg} / \mathrm{m}^{2}$, respectively. These are summarised in Table 1.

The mean eGFR was $62.9 \pm 21.2$, and this significantly increased from group 1 to $4(p<0.001)$. Systolic BP slightly reduced across the groups $(p=0.04)$, but diastolic BP increased $(p=0.01)$. No significant differences were found in weight, duration of diabetes, or lipid profiles $(p>0.05)$. On the other hand, there were significant difference in gender $(p<0.001)$; socio-eco- 
Fig. 1. Kaplan-Meier survival analysis plot for the primary endpoint - all cause mortality (log-rank test $p$ value $<0.001)$.

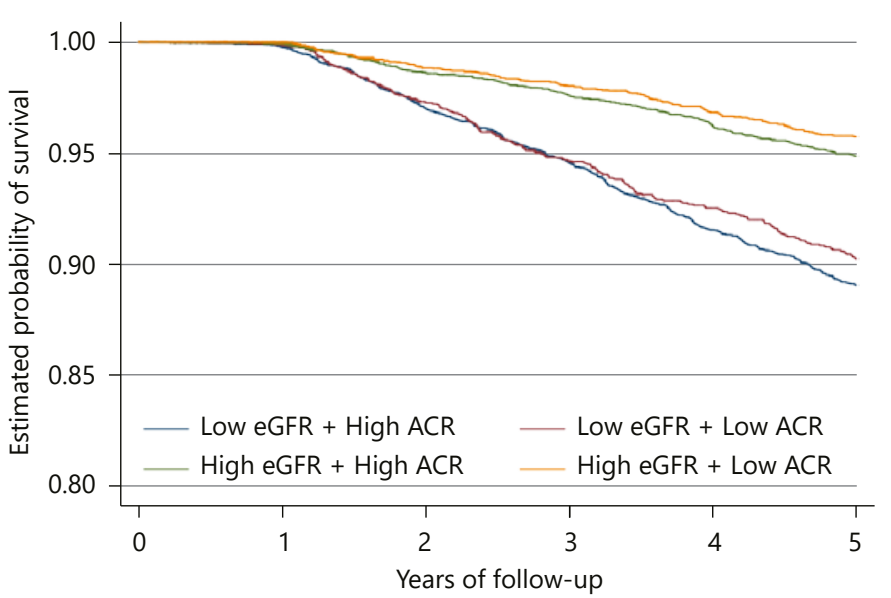

Not at risk (failure) Low eGFR + High ACR Low eGFR + Low ACR High eGFR + High ACR High eGFR + Low ACR

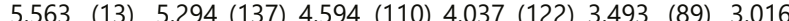
$\begin{array}{lllllllll}2,521 & \text { (3) } & 2,390 & \text { (59) } 2,106 & \text { (54) } & 1,860 & \text { (40) } & 1,649 & \text { (39) } 1,453\end{array}$ $\begin{array}{lllllllllll}5,511 & \text { (3) } & 5,222 & (65) & 4,555 & \text { (44) } & 4,023 & \text { (51) } & 3,542 & \text { (48) } & 3,080\end{array}$

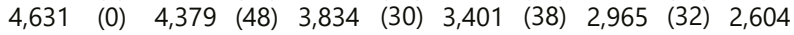

nomic status $(p<0.001)$; smoking and alcohol status $(p<0.001)$; and BMI $(p=0.018)$ between the study groups (Table 1).

\section{Primary Endpoint - Risk of All-Cause Mortality and \\ CV Events \\ Crude Mortality Rates}

There were 1,025 deaths in the study population after a 5-year follow-up period, with a total follow-up time of 71,624 person-years. The proportion of mortality significantly decreased across the group from $8.5 \%$ in group 1 to $3.2 \%$ in group 4 ( $p$ value for trend $=0.012$ ). Similarly, the 5-year probability of survival for all-cause mortality was significantly lower in group $1(89 \%)$ than in group 2 (90\%), group 3 (95\%), and group 4 (96\%) (log-rank test $p$ value $<0.001$; Fig. 1$)$. The overall crude mortality rate was 14.3 per 1,000 person-years (95\% CI 13.5-15.2) with the greatest mortality rate in group $1-21.7$ per 1,000 personyears (95\% CI 19.8-23.7) and the least in group 4-8.1 per 1,000 person-years (95\% CI 6.9-9.5; Fig. 2).

\section{Risk of All-Cause Mortality}

Compared to group 1 (patients with low eGFR + high ACR), the risk of all-cause mortality was $6 \%$ lesser (aHR: 0.94; 95\% CI 0.79-1.12) in group 2; 20\% lesser (aHR: 0.80; 95\% CI 0.68-0.96) in group 3; and 28\% lesser; (aHR: 0.72; 95\% CI 0.59-0.87) in group 4, following adjustment for confounders (Table 2).

Reduced eGFR and Increased Urinary ACR as Powerful Determinants of Survival

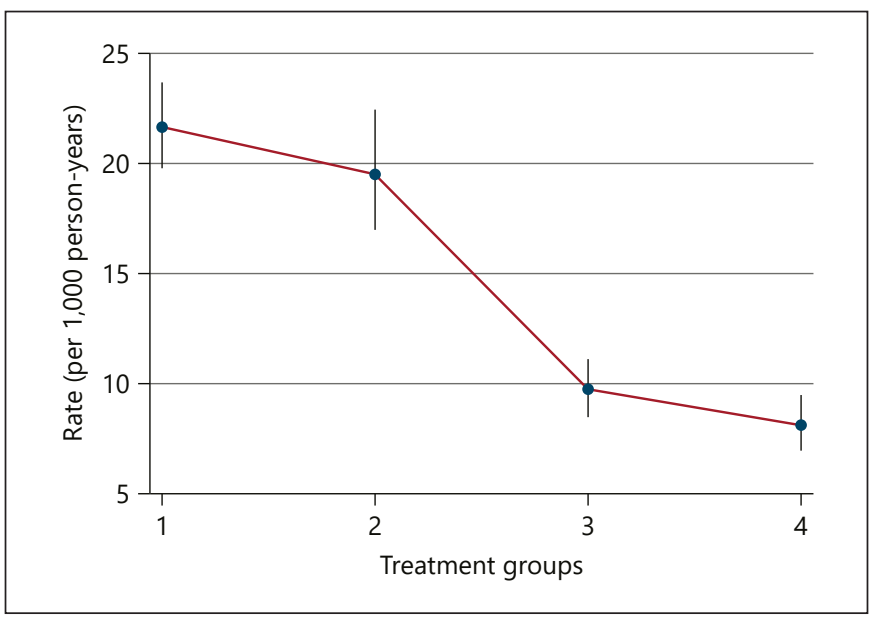

Fig. 2. Graph of the crude incidence rate for primary endpoint all-cause mortality. Group 1: low eGFR + high ACR (eGFR $<60$ and ACR $\geq 300$ ); group 2: low eGFR + low ACR (eGFR $<60$ and ACR <300); group 3: high eGFR + high ACR (eGFR $\geq 60$ and ACR $\geq 300$ ); and group 4: high eGFR + low ACR (eGFR $\geq 60$ and ACR $<300)$.

\section{Secondary Endpoints - Risk of Composite MACE and CV Events \\ Crude Event Rates}

As shown in Table 2, a total of 1,794 composite events of MACE occurred after a 5-year follow-up period, amounting to 63,698 person-years. This signified a 
Table 2. Comparison of number of events, incidence rate, and risk of the primary and secondary endpoints between the treatment groups

\begin{tabular}{|c|c|c|c|c|c|}
\hline Categories & $\begin{array}{l}\text { Group 1: low } \\
\text { eGFR + high ACR }\end{array}$ & $\begin{array}{l}\text { Group 2: low } \\
\text { eGFR + low ACR }\end{array}$ & $\begin{array}{l}\text { Group 3: high } \\
\text { eGFR + high ACR }\end{array}$ & $\begin{array}{l}\text { Group 4: high } \\
\text { eGFR + low ACR }\end{array}$ & Total \\
\hline & $n=5,563$ & $n=2,522$ & $n=5,511$ & $n=4,631$ & $n=18,227$ \\
\hline \multicolumn{6}{|l|}{ All-cause mortality } \\
\hline Events/person-years, $n$ & $471 / 21,747$ & $195 / 9,999$ & $211 / 21,645$ & $148 / 18,233$ & $1,025 / 71,624$ \\
\hline Absolute rate $(95 \% \mathrm{CI})$ & $21.7(19.8-23.7)$ & $19.5(17.0-22.4)$ & $9.7(8.5-11.2)$ & $8.1(6.9-9.5)$ & $14.3(13.5-15.2)$ \\
\hline $\mathrm{aHR}^{\mathrm{b}}(95 \% \mathrm{CI})$ & 1 (reference) & $0.94(0.79-1.12)$ & $0.80(0.68-0.96)$ & $0.72(0.59-0.87)$ & - \\
\hline \multicolumn{6}{|c|}{ Three-point composite MACE } \\
\hline Events/person-years, $n$ & $773 / 18,604$ & $324 / 8,681$ & $400 / 19,638$ & $297 / 16,774$ & $1,794 / 63,698$ \\
\hline Absolute rate $(95 \% \mathrm{CI})$ & $41.5(38.7-44.6)$ & $37.3(33.5-41.6)$ & $20.4(18.5-22.5)$ & $17.7(15.8-19.8)$ & $28.2(26.9-29.5)$ \\
\hline $\mathrm{aHR}^{\mathrm{b}}(95 \% \mathrm{CI})$ & 1 (reference) & $0.93(0.82-1.07)$ & $0.82(0.72-0.93)$ & $0.73(0.63-0.84)$ & - \\
\hline$p$ value & - & 0.319 & 0.002 & $<0.001$ & - \\
\hline$p$ value & - & 0.486 & $<0.001$ & $<0.001$ & - \\
\hline
\end{tabular}

CI, confidence interval; aHR, adjusted hazard ratio. ${ }^{a}$ Absolute rate at 1,000 person-years. ${ }^{b}$ Adjusted for age, gender, duration of diabetes, systolic blood pressure, diastolic blood pressure, $\mathrm{HbA1c}$, and socio-economic status.

crude event rate of 28 per 1,000 person-years $(95 \%$ CI 27-30). Group 1 had the greatest proportion of events (Table 2), as well as the lowest probability of survival (80\%) compared to 83,90 , and $91 \%$ in groups 2,3 , and 4 , respectively, after 5 years (log-rank test $p$ value $<0.001$; Fig. 3a).

Similarly, a total of $764 \mathrm{CV}$ events were recorded after 5 years (crude event rate: 12 per 1,000 person-years; within a total of 63,746 person-years. The crude incidence rates of CV events significantly decreased from groups 1 to 4 ( $p$ value for trend $<0.001$ ). Similarly, the 5 -year survival curve showed the same pattern (log-rank test $p$ value $<0.001$; Fig. 3b).

Risk of Composite MACE and CV Events

Table 2 also shows that the risk of composite MACE was 7\% lesser (aHR: 0.93; 95\% CI 0.82-1.07) in group 2; $18 \%$ lesser (aHR: 0.82 ; 95\% CI 0.72-0.93) in group 3; and 27\% lesser; (aHR: 0.73; 95\% CI 0.63-0.84) in group 4 compared to group 1 patients (with low eGFR + high ACR) following adjustment for confounders. A similar pattern was shown in the risk of CVs in which there were 7,40 , and $46 \%$ reductions in the risk of stroke and myocardial infarction in groups 2,3 , and 4 , respectively, compared to group 1 (Table 2).

\section{Discussion}

In this study of 18,227 patients with insulin-treated T2D, we found that the combination of reduced eGFR with increased ACR was associated with the greatest risk of premature death, followed closely by those with reduced eGFR and normal ACR levels. This observation demonstrates that quantitative information about eGFR and albuminuria status is an independent predictor of total mortality, thus expanding prior observations and supporting the hypothesis that eGFR and ACR provide synergistic insight into the association between diabetic kidney disease and total mortality risk, even in this cohort of insulin-treated T2D, which by definition is at high risk of $\mathrm{CV}$ disease and mortality. Interestingly, we observed that individuals with reduced eGFR but normal ACR had a higher risk of mortality compared with those with normal eGFR but raised ACR.

While it had long been recognised that individuals with reduced eGFR had high rates of CV disease, it was not until 2004 when Go et al. [24] demonstrated a large exponential increase in the age-standardised rate for allcause mortality and CVs over a 3-year period in subjects with eGFR $<60 \mathrm{~mL} / \mathrm{min}$. Subsequently, the CKD Prognosis Consortium [9] provided a more comprehensive evidence about the prognostic impact of eGFR and albumin- 
Fig. 3. Kaplan-Meier survival analysis plots for the secondary endpoint. a Three-point composite of MACE (log-rank test $p$ value $<0.001)$. b CV events (log-rank test $p$ value $<0.001)$. a

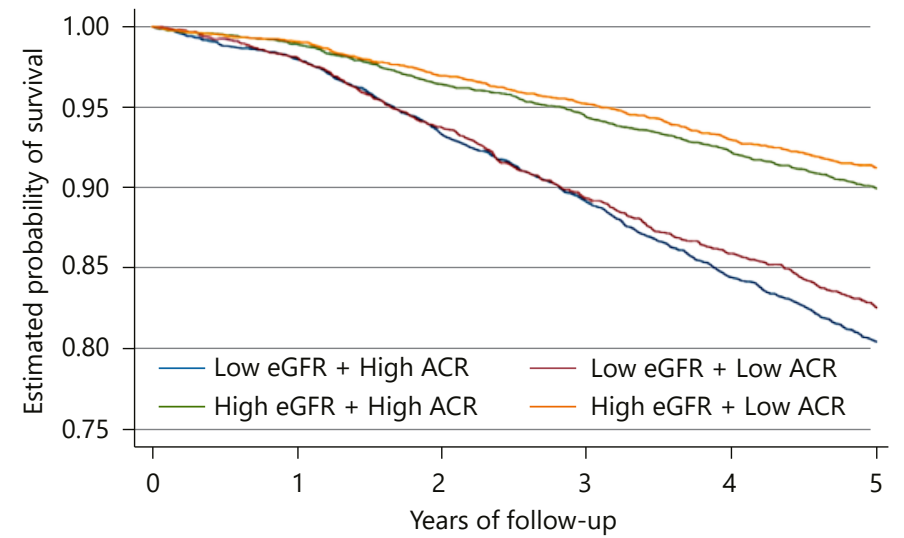

Not at risk (failure)

Low eGFR + High ACR 4,878 (98) 4,558 (204) 3,931 (168) 3,421 (171) 2,948 (132) 2,547

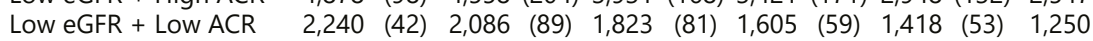

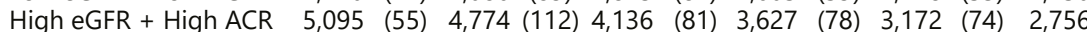

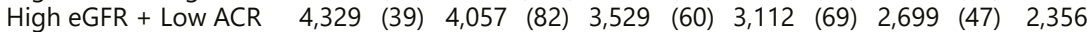

b

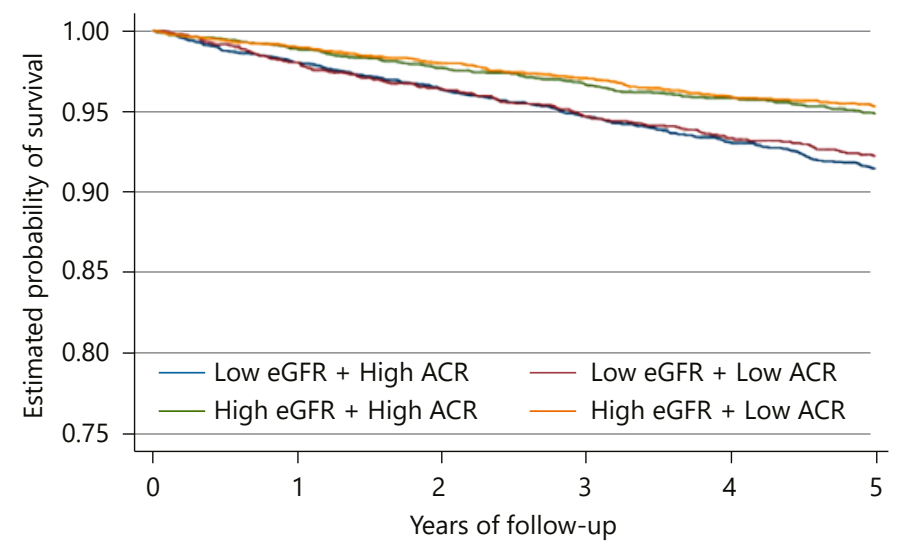

Not at risk (failure)

$\begin{array}{llllllllllll}\text { Low eGFR + High ACR } & 4,878 & \text { (85) } & 4,567 & \text { (66) } & 3,937 & \text { (58) } & 3,429 & \text { (48) } & 2,950 & \text { (42) } & 2,550\end{array}$

Low eGFR + Low ACR $\quad 2,241 \quad$ (39) 2,089 (30) 1,827 (27) 1,606 (19) 1,419 (14) 1,253

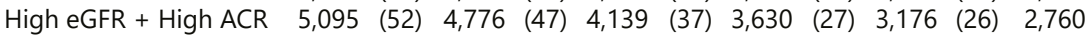

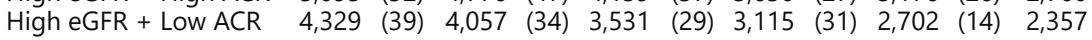

uria on mortality and kidney outcomes. In addition to eGFR, proteinuria, either measured as total urinary protein or as urine albumin, is also a potent predictor of mortality and CV risk $[1,2]$. This was again supported by the observation from the CKD Prognosis Consortium which demonstrated a linear increase in the risk of all-cause and CV mortality as the urinary ACR increases [9]. This increase in risk is independent of eGFR such that there is an additive effect of proteinuria on the risk of death or events at any level or stage of GFR.

While both eGFR and albuminuria independently associate with an increased risk of $\mathrm{CV}$ disease, a key question for the practising clinician is whether they add anything to improve mortality prediction above the known traditional risk factors for CV disease such as age, hypertension, or hyperlipidaemia among individuals who are already at high risk of premature death - as is the case in our insulintreated cohort here. To this end, our analysis for eGFR and albuminuria as a predictor of total mortality, has indeed independently adjusted for conventional CV risk factors. In contrast to our study, in the analysis of 27,000 patients in the TRANSCEND and ONTARGET randomised clinical trial who were at high CV risk, the addition of eGFR and albuminuria did not amount to a reduction in the number of subjects classified into the intermediate risk group [25]. Finally, the PREVEND study group assessed 
the value of kidney measure to predict a composite endpoint of all-cause and CV mortality as well as incident CV events [26]. In this study, both eGFR and albuminuria were assessed separately against a model using Framingham CV risk factors. Albuminuria but not eGFR was associated with improved risk prediction. Of note, none of these studies were conducted specifically in people with T2D. Thus, individuals with T2D, specifically those who are on insulin, represent a unique patient cohort for mortality prediction, and combining eGFR and albuminuria offers additional prognostication for mortality outcome. However, whether increased ACR or reduced eGFR is a cause or simply a marker of mortality risk such that reducing ACR or increasing eGFR would improve mortality outcomes remains unclear and is beyond the remit of this present study. Nonetheless, in the context of albuminuria in people with T2D, recent data suggest that in addition to renin-angiotensin system inhibitors, several glucose-lowering treatments, such as sodium-glucose cotransporter-2 inhibitors $[27,28]$ and glucagon-like peptide- 1 agonist $[29,30]$, have been shown to improve ACR, as well as CV mortality outcomes and induce weight loss. While the mechanism for the reduction of mortality outcome remains unclear, concurrent use of a glucose-lowering therapy with insulin is used widely. In a previous study within this same population cohort, we showed that the use of GLP-1 with insulin was associated with reduced $\mathrm{CV}$ events and total mortality compared with insulin alone [23]. Thus, the identification of patients at a high risk of CV events based on ACR and eGFR status would not only trigger the application of an aggressive $\mathrm{CV}$ reduction strategy, but also a concurrent use of appropriate glucose-lowering therapies with favourable effects on weight, albuminuria, and CV outcomes.

While it is likely that the majority of patients within this cohort have CKD due to diabetic nephropathy, it is conceivable that other underlying aetiologies of albuminuria associated with CKD are also present. Specifically, obesity-related glomerulopathy has increasingly been reported in more and more obese patients without overt diabetes and pre-existing renal diseases [31]. It is a secondary form of focal and segmental glomerulosclerosis (FSGS) manifested as proteinuria and progressive renal dysfunction [32]. This is relevant within this cohort due to the well-recognised association between insulin treatment with adverse weight outcomes. Furthermore, previous studies have shown that a weight loss intervention benefited the remission of proteinuria in patients with obesity-related glomerulopathy [33].

The main strength of our study derives from the inclusion of a large cohort of patients with T2D receiving insu- lin therapy in a real-world population which is largely representative of the UK population. This implies that our findings will be generalizable to various population that share similar demographics. The large cohort of patients studied here provides adequate statistical power and also contains information on other time-varying covariates to adjust for possible confounders. We adjusted for a large set of factors that could have differed at baseline. Nevertheless, some residual confounding in our study could persist. For example, our classification of albuminuria was largely based on a single measurement, in contrast to current recommendation, in which at least two measurements are required. Nonetheless, a single measure of urinary albumin within a large patient cohort provides a great deal of predictive information. In addition, as is the case in all studies of CV or ESRD risk associated with eGFR and albuminuria, the effect of competing hazards may bias the estimates of risk. This is because elevated ACR and low eGFR are also risk factors for non-renal diseases, and associated differential mortality in high-risk individuals may confound hazard ratio estimates for $\mathrm{CV}$ events. Lastly, changes after baseline in medications and subsequent changes in glycaemic indices or blood pressure were not evaluated in this analysis and therefore cannot account for any differences that might influence the association between ACR and outcomes.

In conclusion, the combination of elevated levels of ACR and reduced eGFR, are independently associated with increased risk of all-cause mortality in insulin-treated patients with T2D, even after adjusting for known CV risk factors. This risk of mortality is followed closely with the group who had reduced eGFR but normal ACR. In view of recent advances in the management of $\mathrm{CV}$ disease and proteinuria in people with $\mathrm{T} 2 \mathrm{D}$, beyond the conventional CV risk management strategy, this information will provide useful information to identify and prognosticate high-risk patients with T2D patients who are on insulin therapy to receive an additional cardio-protective management strategy.

\section{Statement of Ethics}

Ethical approval for this study was obtained from the SouthEast Research Ethics Committee.

\section{Disclosure Statement}

All authors declare no conflicts of interest in relation to the content of this study.
Anyanwagu/Donnelly/Idris 


\section{References}

1 Hemmelgarn BR, Manns BJ, Lloyd A, James MT, Klarenbach S, Quinn RR, et al.; Alberta Kidney Disease Network. Relation between kidney function, proteinuria, and adverse outcomes. JAMA. 2010 Feb;303(5):423-9.

2 Hallan SI, Ritz E, Lydersen S, Romundstad S, Kvenild K, Orth SR. Combining GFR and albuminuria to classify CKD improves prediction of ESRD. J Am Soc Nephrol. 2009 May; 20(5):1069-77.

3 Ishani A, Grandits GA, Grimm RH, Svendsen $\mathrm{KH}$, Collins AJ, Prineas RJ, et al. Association of single measurements of dipstick proteinuria, estimated glomerular filtration rate, and hematocrit with 25-year incidence of endstage renal disease in the multiple risk factor intervention trial. J Am Soc Nephrol. 2006 May;17(5):1444-52.

4 Halbesma N, Kuiken DS, Brantsma AH, Bakker SJ, Wetzels JF, De Zeeuw D, et al. Macroalbuminuria is a better risk marker than low estimated GFR to identify individuals at risk for accelerated GFR loss in population screening. J Am Soc Nephrol. 2006 Sep;17(9):258290.

5 de Boer IH, Rue TC, Hall YN, Heagerty PJ, Weiss NS, Himmelfarb J. Temporal trends in the prevalence of diabetic kidney disease in the United States. JAMA. 2011 Jun;305(24) 2532-9.

6 Kidney Disease Improving Global Outcomes (KDIGO) CKD Work Group. KDIGO 2012 Clinical Practice Guideline for the Evaluation and Management of Chronic Kidney Disease [cited May 8, 2018]. Available from: http:// www.kdigo.org/clinical_practice_guidelines/ pdf/CKD/KDIGO_2012_CKD_GL.pdf. Published January 2013.

7 Levey AS, Becker C, Inker LA. Glomerular filtration rate and albuminuria for detection and staging of acute and chronic kidney disease in adults: a systematic review. JAMA. 2015 Feb;313(8):837-46.

8 Levey AS, Bosch JP, Lewis JB, Greene T, Rogers N, Roth D; Modification of Diet in Renal Disease Study Group. A more accurate method to estimate glomerular filtration rate from serum creatinine: a new prediction equation. Ann Intern Med. 1999 Mar;130(6) 461-70.

9 Fox CS, Matsushita K, Woodward M, Bilo HJ, Chalmers J, Heerspink HJ, et al.; Chronic Kidney Disease Prognosis Consortium. Associations of kidney disease measures with mortality and end-stage renal disease in individuals with and without diabetes: a meta-analysis. Lancet. 2012 Nov;380(9854):1662-73.

10 Holman RR, Paul SK, Bethel MA, Matthews DR, Neil HA. 10-year follow-up of intensive glucose control in type 2 diabetes. $\mathrm{N}$ Engl J Med. 2008 Oct;359(15):1577-89.

11 Ray KK, Seshasai SR, Wijesuriya S, Sivakumaran R, Nethercott S, Preiss D, et al. Effect of intensive control of glucose on cardiovascular outcomes and death in patients with diabetes mellitus: a meta-analysis of randomised controlled trials. Lancet. 2009 May;373(9677): 1765-72.

12 Inzucchi SE, Bergenstal RM, Buse JB, Diamant M, Ferrannini E, Nauck M, et al. Management of hyperglycemia in type 2 diabetes, 2015: a patient-centered approach: update to a position statement of the American Diabetes Association and the European Association for the Study of Diabetes. Diabetes Care. 2015 Jan;38(1):140-9.

13 Russell-Jones D, Khan R. Insulin-associated weight gain in diabetes-causes, effects and coping strategies. Diabetes Obes Metab. 2007 Nov;9(6):799-812.

14 Praga M, Morales E. Obesity, proteinuria and progression of renal failure. Curr Opin Nephrol Hypertens. 2006 Sep;15(5):481-6.

15 Gerstein HC, Miller ME, Byington RP, Goff DC Jr, Bigger JT, Buse JB, et al.; Action to Control Cardiovascular Risk in Diabetes Study Group. Effects of intensive glucose lowering in type 2 diabetes. N Engl J Med. 2008 Jun;358(24):2545-59.

16 van Avendonk MJ, Rutten GE. Insulin therapy in type 2 diabetes: what is the evidence? Diabetes Obes Metab. 2009 May;11(5):41532.

17 Currie CJ, Poole CD, Evans M, Peters JR, Morgan CL. Mortality and other important diabetes-related outcomes with insulin vs other antihyperglycemic therapies in type 2 diabetes. J Clin Endocrinol Metab. 2013 Feb; 98(2):668-77.

18 Roumie CL, Greevy RA, Grijalva CG, Hung AM, Liu X, Murff HJ, et al. Association between intensification of metformin treatment with insulin vs sulfonylureas and cardiovascular events and all-cause mortality among patients with diabetes. JAMA. 2014 Jun; 311(22):2288-96.

19 Herman ME, O’Keefe JH, Bell DS, Schwartz SS. Insulin Therapy Increases Cardiovascular Risk in Type 2 Diabetes. Prog Cardiovasc Dis. 2017 Nov - Dec;60(3):422-34.

20 Muniyappa R, Iantorno M, Quon MJ. An integrated view of insulin resistance and endothelial dysfunction. Endocrinol Metab Clin North Am. 2008 Sep;37(3):685-711.

21 Blak BT, Thompson M, Dattani H, Bourke A. Generalisability of The Health Improvement Network (THIN) database: demographics, chronic disease prevalence and mortality rates. Inform Prim Care. 2011;19(4):251-5.

22 Anyanwagu U, Mamza J, Mehta R, Donnelly $\mathrm{R}$, Idris I. Cardiovascular events and all-cause mortality with insulin versus glucagon-like peptide- 1 analogue in type 2 diabetes. Heart. 2016 Oct;102(19):1581-7.

23 Anyanwagu U, Mamza J, Donnelly R, Idris I. Effect of adding GLP-1RA on mortality, cardiovascular events, and metabolic outcomes among insulin-treated patients with type 2 diabetes: A large retrospective UK cohort study. Am Heart J. 2018 Feb;196:18-27.

24 Go AS, Chertow GM, Fan D, McCulloch CE, Hsu CY. Chronic kidney disease and the risks of death, cardiovascular events, and hospitalization. N Engl J Med. 2004 Sep;351(13): 1296-305.

25 Clase CM, Gao P, Tobe SW, McQueen MJ Grosshennig A, Teo KK, et al.; ONTARGET (ONgoing Telmisartan Alone and in combination with Ramipril Global Endpoint Trial) and TRANSCEND (Telmisartan Randomized Assessment Study in Angiotensin-Converting-Enzyme-Inhibitor Intolerant Subjects with Cardiovascular Disease). Estimated glomerular filtration rate and albuminuria as predictors of outcomes in patients with high cardiovascular risk: a cohort study. Ann Intern Med. 2011 Mar;154(5):310-8.

26 Smink PA, Lambers Heerspink HJ, Gansevoort RT, de Jong PE, Hillege HL, Bakker SJ, et al. Albuminuria, estimated GFR, traditional risk factors, and incident cardiovascular disease: the PREVEND (Prevention of Renal and Vascular Endstage Disease) study. Am J Kidney Dis. 2012 Nov;60(5):804-11.

27 Zinman B, Wanner C, Lachin JM, Fitchett D, Bluhmki E, Hantel S, et al.; EMPA-REG OUTCOME Investigators. Empagliflozin, cardiovascular outcomes, and mortality in type 2 diabetes. N Engl J Med. 2015 Nov; 373(22):2117-28.

28 Cherney DZ, Zinman B, Inzucchi SE, KoitkaWeber A, Mattheus M, von Eynatten M, et al. Effects of empagliflozin on the urinary albumin-to-creatinine ratio in patients with type 2 diabetes and established cardiovascular disease: an exploratory analysis from the EMPAREG OUTCOME randomised, placebo-controlled trial. Lancet Diabetes Endocrinol. 2017 Aug; 5(8):610-21

29 Marso SP, Daniels GH, Brown-Frandsen K, Kristensen P, Mann JF, Nauck MA, et al.; LEADER Steering Committee; LEADER Trial Investigators. Liraglutide and Cardiovascular Outcomes in Type 2 Diabetes. N Engl J Med. 2016 Jul;375(4):311-22.

30 Mann JF, Ørsted DD, Brown-Frandsen K, Marso SP, Poulter NR, Rasmussen S, et al.; LEADER Steering Committee and Investigators. Liraglutide and Renal Outcomes in Type 2 Diabetes. N Engl J Med. 2017 Aug;377(9):839-48.

31 Praga M. Obesity-a neglected culprit in renal disease. Nephrol Dial Transplant. 2002 Jul;17(7):1157-9.

32 Kambham N, Markowitz GS, Valeri AM, Lin J, D’Agati VD. Obesity-related glomerulopathy: an emerging epidemic. Kidney Int. 2001 Apr;59(4):1498-509.

33 Afshinnia F, Wilt TJ, Duval S, Esmaeili A, Ibrahim HN. Weight loss and proteinuria: systematic review of clinical trials and comparative cohorts. Nephrol Dial Transplant. 2010 Apr;25(4):1173-83. 